\title{
Do Spinoffs Create Value in Hong Kong?
}

\author{
Terence Tai-Leung Chong \\ The Chinese University of Hong Kong \\ Daniel Wai-Hong Wong \\ The Chinese University of Hong Kong \\ Venus Khim-Sen Liew \\ Universiti Malaysia Sarawak
}

ABSTRACT

T

here is a broad consensus in the literature that spinoffs tend to create value for shareholders and exhibit positive long-run excess returns. However, most of the prior studies are confined to the US and the European cases. The spinoff problems in Hong Kong are surprisingly under-studied despite its important role as a global center of capital formation. In this paper, we find that there is a short-run value creation for the Hong Kong spinoffs. However, the financial health of the spinoff companies, measured by various financial ratios, tends to deteriorate in the long-run. In general, Hong Kong spinoffs generate negative returns to investors.

\section{Keywords: Spinoff; Value Creation; Cash Ratio; Current Ratio; Debt-to-Equity Ratio}

\section{INTRODUCTION}

Over the last decade, Hong Kong has emerged as a major global center of capital formation. In 2004, Hong Kong overtook major financial centers like Tokyo and London to become the world's third largest market in terms of total equity funds raised. Such performance was mainly due to global interest in the emergence of the Mainland China economy, for which Hong Kong has served as the premier fund-raising platform. According to the statistics of the Hong Kong Stock Exchange, the market capitalization of China-related stocks in the Main Board was less than 5\% of its total market capitalization in 1993. The figure rose to $37 \%$ in 2005 . The large-scale fund raising activities in Hong Kong over the past few years included some of the world's largest IPOs such as China Life Insurance Company and the China Construction Bank. Because of the relatively good market conditions, many companies have taken the opportunity to spin off their businesses.

There is a general consensus in the literature that corporate spinoffs create values for shareholders and exhibit positive long-run excess returns (Veld and Veld-Merkoulova, 2004). Spinning-off unrelated businesses can free managers from operations unrelated to companies' core businesses and eliminate negative synergies between parents and subsidiaries (Schipper and Smith, 1983; Daley et al., 1997; Desai and Jain, 1999). Besides, a firm that is undervalued due to information asymmetry will experience an improvement in market valuation with the separation of its divisions into independently traded units through a spinoff (Gilson et al., 1998; Krishnaswanmi and Subramaniam, 1999; Huson and MacKinnon, 2003). A number of studies have suggested other sources of abnormal returns from corporate spinoffs (Slovin et al, 1995; Shleifer and Vishny, 1997; Allen, 2001; McConnell et al., 2001; Mansi and Reed, 2002). However, most of the aforementioned studies are confined to the US and the European cases. The spinoff cases for Asia have never been investigated. In this paper, we examine if the conventional wisdom on the benefits of spinoffs can be automatically extended to the cases in Hong Kong, the center of capital formation in Asia. The remaining of this paper is organized as follows. The estimation results concerning the spinoff returns for the case of Hong Kong will be presented in Section 2. Section 3 reports the results of company financial ratio analysis. Section 4 concludes the paper.

\section{PERFORMANCE OF THE STOCK PRICES}

We analyze a sample of Hong Kong spinoffs covering the period from January 1994 to June 2003. The subsidiaries divested in the spinoff transactions are identified by checking South China Morning Post articles on Lexis-Nexis. Data on stock prices and the first trading dates of spinoffs are extracted from bigcharts.com. We only consider cases where both parent firms and spinoffs are listed in Hong Kong. A summary of the final sample consisting of 21 spinoffs, together with their business classification are given in Table 1 .

An interesting but unaddressed issue in the literature is whether or not the act of spinoff is to maximize the market value of firms. In this paper, we examine the total market-adjusted value of the combined firm the spinoff. To adjust for the market trend, we also report this total value relative to the total market capitalization of the Hong Kong stock market. The calculated market capitalization ratios of 14 companies before and after spinning off are reported in Table 2.

Table 2 shows that the market capital ratio has increased in 11 out of 14 cases (amounting to 78.57\%) one year after spinning off, but this ratio appears to deteriorate in subsequent years.

In Table 3, the percentage change in market capitalization ratio for

${ }^{1}$ Corresponding author: Terence Chong, Department of Economics, The Chinese University of Hong Kong, Shatin, N.T., Hong Kong. Telephone: 852-26098193. Fax: 852-26035805. Email: chong2064@cuhk.edu.hk. We would like to thank Eric Chou, Julan Du, Kam C. Chan, a referee and those who have made helpful comments to this paper. All errors are ours. 